\title{
IDENTIDADE CULTURAL DA MULHER NEGRA: REPRESENTAÇÕES VISUAIS EM EMBALAGENS DA SEDA ${ }^{1}$
}

\author{
Black women's cultural identity: visual representations \\ in the packaging of the Seda \\ Identidad cultural de la mujer negra: representaciones \\ visuales en envases de la Seda
}

\author{
Maria Ogécia Drigo \\ Universidade de Sorocaba, Sorocaba, Brasil. \\ Doutora em Comunicação e Semiótica pela Pontifícia Universidade Católica de São Paulo (PUC-SP) \\ Mestre em Educação pela Universidade Metodista de Piracicaba (Unimep). \\ E-mail: maria.drigo@yahoo.com.br
}

\section{Graziella A. Malagó}

Universidade de Sorocaba, Sorocaba, Brasil.

Doutoranda do Programa de Pós-Graduação em Comunicação e Cultura da Universidade

de Sorocaba (Uniso). Mestre em Administração pela Universidade Metodista.

E-mail: graziella.malago@prof.uniso.br

RESUMO Objetiva-se verificar que, em meio aos significados gerados por representações visuais de mulheres, podem vir à tona aspectos do processo de construção da identidade cultural da mulher negra, no Brasil. Mbembe, Lipovetsky e Serroy, Semprini e Sodré compõem a fundamentação teórica, e estratégias da semiótica peirceana serão aplicadas na análise de embalagens de produtos para cabelos da marca Seda. O artigo é relevante por contribuir para a compreensão do processo de construção de identidade cultural da mulher negra no Brasil, em momentos tão marcados por conflitos gerados por intolerância às diferenças.

PALAVRAS-CHAVE Mulher negra, Marca, Representação visual.

ABSTRACT We aim to verify that, among the meanings generated by women's visual representations, some aspects of the process of construction of the cultural identity of black women in Brazil can come up. Mbembe, Lipovetsky and Serroy, Semprini, and Sodré compose the theoretical foundation, and we will apply the strategies from Peirce's semiotics in the analysis of hair products packaging from the Seda brand. The article is relevant for contributing to the understanding of the process of construction of the cultural identity of black women in Brazil in a moment pointedly marked by conflicts generated by intolerance to differences.

KEYWORDS Black woman, Brand, Visual representation.

1. Uma versão deste artigo foi apresentada no GI 1 Comunicación, género y diversidad sexual, no XV Congreso de la Asociación Latinoamericana de Investigadores de la Comunicación (Alaic) - Desafíos y Paradojas de la Comunicación en América Latina: las ciudadanías y el poder, Medellín, Colombia, junio 2020. 
RESUMEN El objetivo es verificar, entre los significados generados por representaciones visuales de mujeres, los posibles aspectos del proceso de construcción de la identidad cultural de la mujer negra en Brasil. Mbembe, Lipovetsky y Serroy, Semprini y Sodré componen la fundamentación teórica, y estrategias de la semiótica peirceana se aplicarán en el análisis de los envases de productos para cabellos de la marca "Seda". Se espera que este artículo contribuya a la comprensión del proceso de construcción de la identidad de la mujer negra en Brasil, en un contexto de conflicto generado por la intolerancia a las diferencias.

PALABRAS CLAVE Mujer negra, Marca, Representación visual.

\section{INTRODUÇÃO}

O tema deste artigo é o processo de construção social da identidade cultural da mulher negra. É notória a visibilidade dada aos cabelos em representações visuais de mulheres negras, principalmente nas mídias. No Brasil, há pesquisas realizadas na área de comunicação que estabelecem vínculos entre esse movimento, que envolve os cabelos das mulheres negras e o processo de construção de sua identidade cultural. Em busca realizada no Catálogo de Dissertações e Teses da Coordenação de Aperfeiçoamento de Pessoal de Nível Superior (Capes), em abril de 2019, usando o termo negrura, para a área de Comunicação, encontramos 782 pesquisas. Selecionamos 16 que apresentavam - no título - os termos negro(a) ou preto(a) - e três delas, que envolvem cabelos e a identidade cultural, são agora apresentadas, de modo breve.

Belmiro (2019) trata do processo de construção da identidade negra de uma celebridade da TV brasileira por meio de análise de conteúdo das postagens de uma atriz na rede social Twitter. Entre os resultados, a autora enfatiza que a atriz, enquanto negra, é um referencial de beleza, sucesso e força e sustenta valores da identidade legitimadora branca, uma vez que a identidade negra é tida como sinônimo de resistência, pois a mulher negra ainda sofre com exclusões e preconceitos. Essa dissertação compõe esse breve estado da arte, pois com ela constatamos que os cabelos tiveram um papel de destaque no processo de construção de identidade dessa celebridade.

Arantes (2019), em pesquisa intitulada Celebrando nossos corpos, encrespando nossos fios: a transição capilar como política de visibilidade em narrativas autobiográficas de mulheres negras, buscou resposta à seguinte pergunta norteadora: o quanto ostentar os cabelos crespos e cacheados vai além de uma questão de gosto pessoal, ao pressupor os enfrentamentos a que se está suscetível pela não adequação às normatizações impostas? O corpus da pesquisa se constituiu com narrativas autobiográficas de mulheres negras em destaque nas mídias e que passaram pela transição capilar devidamente midiatizada. Dos resultados, a autora ressaltou que o cabelo crespo vinculado à negritude identifica aspectos culturais e sociais desses grupos enquanto étnicos. E ainda, que a presença dessas mulheres continua sendo exceção nos espaços midiáticos, mesmo considerando distintos contextos da mídia.

Esse Boom é nosso? discursos sobre a transição capilar na publicidade de cosméticos, de Carvalho (2019), é uma pesquisa guiada pela busca de como as grandes marcas de cosméticos capilares, a princípio alinhadas a um discurso hegemônico patriarcal e racista sobre beleza e feminilidade, têm conseguido se aproximar de pautas ligadas aos movimentos sociais, como os que envolvem a valorização positiva e consequente politização dos cabelos naturalmente crespos e cacheados. Sendo assim, o propósito 
da pesquisa era compreender como se dá a aproximação entre o discurso publicitário da marca de cosméticos capilares “Seda”, pertencente ao grupo Unilever, e o discurso de autoaceitação defendido por youtubers crespas e cacheadas em suas ações de divulgação dos produtos "Seda Boom", em 2017, observando especificamente quais valores e representações do feminino e da negritude emergem da interação entre as duas instâncias. Entre os resultados, a autora destaca que a análise dos vídeos sobre texturização e a exploração da história dos produtos da marca Seda, dos últimos anos, mostram que os cabelos sem forma são indesejáveis e essa mesma recusa fica aparente no conteúdo da campanha "Seda Boom". Assim, os cabelos desejáveis - com cachos bem definidos - dão lugar aos alisados e eliminam os cabelos soltos, sem tratamento específico, com cachos irregulares e frizz, “desorganizado”, bem como valores e padrões estéticos regulatórios ainda rígidos para os corpos e cabelos dessas mulheres vão na contramão do discurso emancipatório defendido pelas youtubers escolhidas como embaixadoras da marca. Neste artigo também tratamos da marca Seda, mas vamos dar atenção às representações visuais presentes em embalagens de produtos para cabelos.

$\mathrm{O}$ artigo tem como objetivo geral contribuir para a compreensão do processo de construção da identidade cultural da mulher negra, e como objetivos específicos, apresentar questões da construção de identidade do negro, conforme Mbembe (2017). Para inventariar significados postos em movimento pelas embalagens de produtos da Seda, são analisadas embalagens de produtos para cabelos lançadas pela marca em 1998, 2003 e 2017. A análise envolve a aplicação de estratégias propostas por Santaella (2018), também aplicadas em Drigo e Souza (2013), que se fundamentaram na gramática especulativa, um dos ramos da semiótica, ou lógica, de Charles Sanders Peirce. Elas demandam do analista três tipos de capacidade: a primeira, contemplativa, isto é, a de abrir as janelas da mente e ver o que está diante dos olhos; a segunda, de observar, saber distinguir, discriminar resolutamente diferenças e, por fim, a terceira, de generalizar as observações em classes ou categorias abrangentes. As análises serão permeadas por reflexões sobre marcas como objetos semióticos e sobre o pensamento de Mbembe (2017) e de Sodré (1999) relativas ao negro.

Iniciamos com ideias de Mbembe (2017).

\section{O PROCESSO DE CONSTRUÇÃO DE IDENTIDADE CULTURAL DO NEGRO}

O termo Negro, segundo Mbembe (2017), aparece no início do século XVI, mas se torna de uso corrente apenas no século XVIII, no auge do tráfico de escravos. Desde então, muito antes de adentrar o capitalismo emergente dos séculos XV e XVI, tal ser humano era visto como um ser "vivo e com formas bizarras, queimado pela irradiação do fogo celeste, dotado de uma petulância excessiva, dominado pela alegria e abandonado pela inteligência”. Em relação ao acoplamento África/Negro, Mbembe (2017) esclarece que os valores atribuídos a um ou ao outro os confundem - até os dias atuais -, tanto que "se a África tem um corpo e se ela é um corpo, um isto, é o Negro²

2. Mbembe (2017) usa o termo "Negro" e não "negro”, ou seja, usa o termo com a inicial maiúscula. "Negro" não é um homem da cor preta, mas o ser humano de cor preta enquanto sujeito de raça (independentemente do gênero) e depois como alguém que constrói sua identidade, a partir do território em que vive. Tal sujeito é constituído pelo que o autor denomina de "razão negra". 
que o concede - pouca importa onde ele se encontra no mundo. E se Negro é uma alcunha, se ele é aquilo, é por causa da África”. E quanto à força, se ele a possui, as suas ações não poderiam ser conduzidas senão pela "força bruta do corpo, excessivo, convulsivo e espasmódico, refratário ao espírito, com um misto de acessos, raiva e nervosismo, sendo normal despertar desgosto, medo e terror" (MBEMBE, 2017, p. 76).

A razão negra se constitui com múltiplas vozes, "enunciados e discursos, saberes, comentários e disparates, cujo objeto é a coisa ou as pessoas de 'origem africana' e aquilo que afirmamos ser o seu nome e a sua verdade (os seus atributos e qualidades, o seu destino e significações enquanto segmento empírico do mundo)" (MBEMBE, 2017, p. 57). Explica o mesmo autor que tal razão data da Antiguidade, mas na Idade Moderna ela se consolida com as narrativas dos viajantes, dos exploradores e, em última instância, com uma ciência colonial, que visava ao africanismo. As sociedades eruditas, exposições universais, coleções de amadores de "arte primitiva" também contribuíram para transformar a razão negra numa espécie de senso comum.

Tal sistema de narrativas e discursos codificou "as condições de surgimento e de manifestação da questão da raça, à qual chamaremos de Negro ou, mais tarde e já no tempo colonial, o Indígena” (MBEMBE, 2017, p. 58). Em tal contexto, tratava-se de esclarecer quem é o Negro, como identificá-lo, em que ele era diferente, como torná-lo semelhante e, por fim, como governá-lo para que ele alcançasse tal patamar. Tratava-se, portanto, de responder à questão “Quem é?”, o que formaria a consciência ocidental do Negro:

[...] tanto um conjunto de discursos como de práticas - um trabalho cotidiano que consistiu em inventar, contar, repetir e pôr em circulação fórmulas, textos, rituais com o objetivo de fazer acontecer o Negro enquanto sujeito de raça e exterioridade selvagem, passível a tal respeito, de desqualificação moral e de instrumentalização prática.

(MBEMBE, 2017, p. 58)

Essa seria a primeira etapa do processo de construção da identidade cultural do Negro. Com o tempo, a razão negra suscita outros questionamentos, colocados agora, como explica Mbembe (2017), na primeira pessoa do singular: “'Quem sou eu?'. 'Serei eu, em boa verdade, quem dizem que eu sou?’. 'Será verdade que não sou nada a não ser isto a minha aparência, aquilo que se diz e se quer de mim?'. 'Qual é o meu verdadeiro estado civil e histórico?’” (p. 58-59). As respostas a tais questões constituem a segunda etapa do processo de construção de identidade cultural, que, conforme ressalta Mbembe (2017), nela "o Negro diz de si mesmo que é aquilo que não foi apreendido; aquele que não está onde se diz estar, e muito menos onde o procuramos, mas antes no lugar onde não é pensado" (p. 59).

Essa fase requer arquivos, que são indispensáveis para restituir a História. No entanto, os vestígios, no mais das vezes, não foram preservados. Restam, portanto, fragmentos de uma experiência também fragmentada, "a de um povo em pontilhado, lutando para se definir [...] como uma comunidade cujas manchas de sangue são visíveis em toda a modernidade" (MBEMBE, 2017, p. 60). O autor ainda enfatiza que a declaração de identidade produz textos que se revelam ambíguos, pois ela precisa conjugar a estrutura de submissão presente na primeira fase, assim como a escrita de luta que ressignifica a experiência originária, com a verdade dele próprio em seu território. 
Não devemos considerar que a raça é efeito interno do olhar do outro, ou efeito da percepção, mas que é uma maneira de afirmar força, que demanda que ela seja transformada "em imagem, forma, superfície, figura e, sobretudo, imaginário” (MBEMBE, 2017, p. 65). A raça ou o racismo, conforme o autor, engendram substitutos, equivalentes, máscaras para o rosto humano, que o encobrem e o colocam em segundo plano. No lugar do rosto humano, a raça ou o racismo fazem renascer um rosto de fantasia e uma silhueta, que substitui o rosto e o corpo do homem e ainda, além de ser uma força de desvio do real impregnada de afetos, é também um distúrbio psíquico, que faz que o conteúdo reprimido aflore brutalmente. Assim, para Mbembe (2017), a raça é "um aquém e um além do ser. É uma operação do imaginário, o lugar onde se encontram as regiões obscuras e sombrias do inconsciente” (p. 66).

“Aquele a quem é atribuída uma raça não é passivo” (MBEMBE, 2017, p. 67), uma vez que ele está preso a uma silhueta que o separa da sua essência. Tal separação o leva a odiar aquilo que é e o faz tentar ser aquilo que não é. O oprimido, por sua vez, é acometido de um desejo, obscuro e tenebroso, o de comunidade. Mbembe (2017) explica que o sentimento de perda promove a inovação da raça, assim como a "ideia segundo a qual a comunidade foi cindida, que está ameaçada de extermínio, e que é imperioso voltar a fundála restituindo-lhe uma linha de continuidade para além do tempo, do espaço e da deslocação” (p. 69).

O processo de construção da identidade cultural do Negro pode ser observado também no Brasil, como propõe Sodré (1999), numa base social clara/escura, que tratamos a seguir.

\section{CLAROS E ESCUROS}

Muniz Sodré (1999) enfatiza que as etnias - devido a diferenças de cor e outros aspectos do corpo - são artefatos conceituais usados para desenvolver mecanismos de controle social quando da construção do Estado e, gradativamente, a percepção imediata classifica, por meio dessas noções, grande parte das diferenças fenotípicas. De modo geral, "há apenas os brancos e outros. O mestiço é o cruzamento de duas raças" (SODRÉ, 1999, p. 196) e, impregnada na mestiçagem, está a ideia de uma raça "capaz de resolver o problema da distância entre o paradigma branco-europeu e a diversidade das pigmentações de pele humana no mundo" (SODRÉ, 1999, p. 192).

No Brasil, enfatiza o autor, as palavras mestiço, mulato e moreno mesclam conhecimentos da biologia e da cultura para tornar evidente que mestiçagem é uma singularidade do processo civilizatório, que envolve aspectos culturais e sexuais. Mas há uma superioridade do claro permeando a relação claro/escuro. No processo de construção da identidade cultural do negro, portanto, não se trata de que ele queira "passar por branco, mas de passar por mestiço (mixed). Mesmo quando o indivíduo já se sabe resultante de um cruzamento do mais claro com o mais escuro, torna-se imperativo parecer, ou seja, investir em recursos estéticos da cor hegemônica, que é a clara” (SODRÉ, 1999, p. 212). Essa afirmação de Sodré (1999) vai ao encontro do que Mbembe (2017) explica sobre aquele que está preso a uma raça, quando tenta ser o que não é. Daí o clareamento da pele, o alisamento dos cabelos.

A partir do início dos anos 1990 forma-se "uma espécie de base social (clara e escura)" (SODRÉ, 1999, p. 248). A mídia e a indústria de cosméticos 
contribuem para reforçar o clareamento, tanto por lançar raios dourados sobre a pele negra como pela criação de produtos com potencial para alisar os cabelos, tentando assim aplacar um problema: a pele preta e os cabelos desorganizados. "É um equívoco colocar a cor como traço principal da raça. A cor da pele não importa tanto quanto o tipo do cabelo, pois o cabelo liso-ondulado e comprido sempre codifica mulher 'escura' como ‘mulata”' (SODRÉ, 1999, p. 254). Ainda sobre o cabelo, Sodré (1999) esclarece:

Na verdade, a observação empírica das relações sociais demonstra que importam a cor e o cabelo. Mas o senso comum, a canção popular, a ansiedade visível no que diz respeito a cabelos- tudo isso parece corroborar a ideia de que o pelo é de algum modo estratégico na revalorização identitária. [...] A obsessão contemporânea com o cabelo explica-se igualmente pelo fato de que o atual discurso mediático sobre o negro é mais estético do que político, doutrinário ou ético. (p. 254)

Tal estética, conforme Sodré (1999), não está vinculada à teoria clássica do belo e tampouco se reporta ao esteticismo difuso da sociedade de massa contemporânea, mas à estesia enquanto sinônimo de compartilhamento de sensações e de emoções de um grupo de pessoas por meio da contemplação do objeto. Acrescenta ainda o mesmo autor, que o processo de construção da identidade cultural do negro envolve um saber comum sustentado por uma longa tradição ocidental de preconceitos e rejeições, e que são testemunhos desse movimento os estereótipos e as folclorizações em torno de todo individuo de pele escura que ainda reinam em diversas modalidades de produtos midiáticos, bem como compõem o cotidiano das pessoas, em geral.

Na contramão desse movimento, Sodré (1999) destaca a emergência do paradigma africano, que consiste em levar o negro a exibir a força de sua aparência. Nesse momento, torna-se profícuo olhar para os cabelos cacheados ou crespos. O mercado, por sua vez, prontamente identifica esses novos consumidores, ou seja, milhões e milhões de cidadãos com cabelos crespos. Talvez a possível ressignificação da aparência seja um caminho para iniciar a desestabilização dos alicerces de:

uma sociedade esteticamente regida por um paradigma branco - por mais difícil que seja hoje manejar a ideia de uma identidade cultural fundada em critérios de raça -, a clareza ou a brancura da pele, mesmo sem as barreiras guetificantes do multiculturalismo primeiro-mundista, persiste como marca simbólica de uma superioridade imaginária atuante em estratégias de distinção social ou de defesa contra as perspectivas 'colonizadoras' da miscigenação, da coexistência com imigrantes cada vez mais numerosos nos fluxos da globalização. (SODRÉ, 1999, p. 234)

Antes de avaliar a contribuição da emergência desses cabelos crespos no nosso meio - permitindo a construção de um novo olhar para o negro -, apresentamos produtos para cabelos da linha Seda e com eles - ou mais especificamente, com análises das representações visuais de mulheres, nas embalagens - buscamos explicitar o movimento das etapas do processo de construção da identidade cultural do negro, no Brasil.

\section{A SEDA E OS CABELOS CRESPOS}

Consideramos, de um lado, na perspectiva de Semprini (2006), que a marca é um símbolo, é algo geral e, portanto, se atualiza. A embalagem 
é uma atualização da marca, uma vez que, em certa medida, ela traduz a marca, a representa, assim como os produtos propriamente ditos. De outro, no contexto em que a lógica das marcas envolve contextos sociais e culturais, conforme Lipovetsky e Serroy (2011), elas - via publicidade ou outras manifestações, entre elas as embalagens - propõem significados e valores bem-vindos a diversos contextos culturais. Sendo assim, no caso de produtos específicos para cabelos, é possível identificar os significados neles engendrados e que se reportam, no caso, à mulher negra.

As embalagens dos produtos Seda são vistas, portanto, como signos, na perspectiva da semiótica peirceana. Analisá-las implica utilizar estratégias advindas dessa semiótica para inventariar os efeitos que podem gerar num intérprete qualquer, que pode ser eventualmente o consumidor. Tais efeitos são provocados pelos aspectos qualitativos da embalagem - forma, cores, texturas, palavras e imagens -; pelos aspectos referenciais - pistas engendradas na embalagem e que remetem o intérprete a outros existentes, a objetos ou situações reais e, por fim, pelos aspectos gerais compartilhados culturalmente que a impregnam.

Para tanto, o analista deve se munir de três tipos de olhar: contemplativo, observacional e generalizante, conforme preconiza Santaella (2018), como mencionamos anteriormente. O primeiro olhar é o que capta os aspectos qualitativos; o segundo, elenca as pistas; o terceiro permite generalizar a partir dos aspectos qualitativos e referenciais elencados. Vejamos o que esses tipos de olhar captam nas três embalagens dos produtos da marca Seda. Iniciamos pelas embalagens de xampu e de creme hidratante (Figura 1), lançadas em 1998.

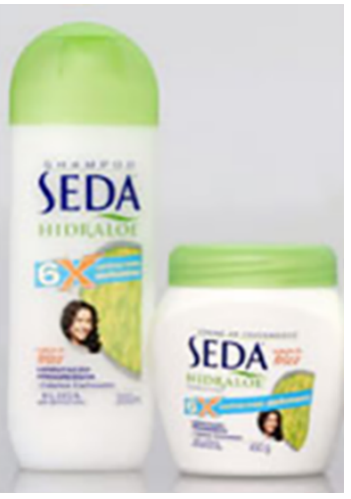

Figura 1. Cabelos cacheados limpos.

Fonte: Unilever (2012).

Iniciamos com os aspectos qualitativos. As cores branca, verde e azul que predominam na embalagem geram sensações de leveza e assepsia. A cor verde, aliada à branca, constrói uma ambiência de segurança e tranquilidade. O formato e os sulcos na parte verde convidam o consumidor ao tato. Isso é gerado por um olhar que se mantém um pouco distante da embalagem, pois, ao aproximar o olhar, o consumidor se vê diante de uma profusão de informações. A imagem e a mistura de cores nas palavras levam o consumidor - ou alguém que esteja diante desse objeto - a desviar o olhar. Nesse aspecto, é pouco provável que a embalagem - enquanto signo - gere efeitos emocionais, ou seja, ela é pouco convidativa ou sedutora para o consumidor.

Há sim a possibilidade de que o intérprete permaneça nas pistas exibidas, como a reprodução da fotografia de uma mulher de cabelos cacheados, bem como o tipo de produto e a marca anunciados, 
em letras azuis e maiúsculas, que contribuem para a identificação do produto, de modo abrupto. Vale enfatizar que a imagem na embalagem reprodução de uma fotografia - é uma forma figurativa como registro físico, com conexão direta com o real, o que, conforme Santaella (2001), contribui para firmar o efeito de constatação, de identificação, no caso, do produto e da marca, bem como de sua utilidade. Trata-se de um xampu para cabelos cacheados da marca Seda.

Para algum consumidor cujo repertório envolve conhecimentos sobre design de embalagens ou sobre o percurso da Seda no mercado, é possível que os efeitos gerados pela embalagem envolvam aspectos de sua criação, da qualidade do produto, ou sobre sua aceitação no mercado. No contexto do artigo, é importante salientar que esse produto mostra que o mercado de cosméticos se volta para diferentes tipos de cabelos, ou seja, que considera a possibilidade da existência de cabelos cacheados.

Aqui podemos inferir que, como menciona Sodré (1999), o africanismo não estava em alta. O mercado ainda se mantinha preocupado com os cremes alisantes. Era o cabelo liso aliado ao claro que ia ao encontro do ideal, era o domínio do claro. Em relação ao processo de construção da identidade cultural do negro, na perspectiva de Mbembe (2017), essas embalagens são pistas que nos remetem ao primeiro passo do processo, em que o negro ainda não diz de si, mas busca a aparência do claro.

Há também os aspectos generalizantes da cor que reverberam. A cor branca remete o consumidor à pureza e a cor verde, à tranquilidade, à segurança. Assim, o produto pode ser visto como aquele capaz de promover uma assepsia, de trazer a pureza à tona. Embora os cabelos sejam crespos - o que pode remeter o usuário à mulher "mulata", seguindo a nomeação mencionada por Sodré (1999) - ele seguramente promove uma limpeza, torna a "mulata" mais clara.

Em 2000, a Seda lança a linha Keraforce. Novas pistas aparecem com a embalagem de 2003 (Figura 2). A embalagem de xampu da nova linha dá destaque ao escuro, pois os cabelos cacheados e a pele negra se tornam visíveis.

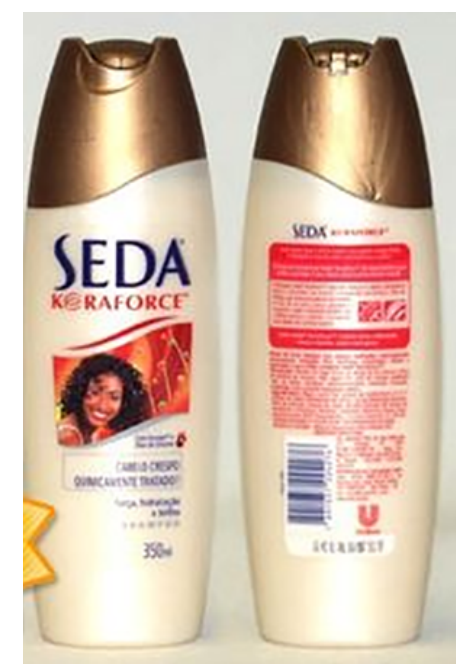

Figura 2. A vez do escuro.

Fonte: Unilever (2012).

Os tons bege, avermelhado e terroso constroem uma ambiência calorosa, sensual e impregnada de força. Os sulcos e as formas arredondadas da embalagem contribuem para agregar movimento e sensualidade. 
Os efeitos gerados são provenientes dessa ambiência calorosa e sensual, gerada pelas cores e formas mencionadas, que se associada ao escuro, pelo consumidor, reverbera estereótipos da mulher negra. Martins (2009) relata que, em pesquisas envolvendo anúncios publicitários, as pessoas de cor preta são representadas em releituras de estereótipos do século XIX, explícitas em categorias: atleta, artista, trabalhador braçal, pessoa carente, mulata e africano, e a mulata continua no imaginário social como objeto sexual, como uma figura exótica. Vejamos os aspectos referenciais. A reprodução fotográfica exibe uma mulher de cabelos cacheados e com pele escura, o que contribui para a identificação imediata do produto pelo consumidor.

Considerando-se os modos de sugerir, apresentar ou representar um objeto, por semelhança, Santaella (2001) tenta abarcar todos os modos possíveis, propondo três formas: não-representativas, figurativas e representativas. As formas figurativas, conforme Santaella (2001), transpõem objetos tridimensionais para planos bidimensionais e prevalecem como formas referenciais, pois, em alguma medida e com diversos graus de ambiguidade, apontam para objetos ou situações reconhecíveis. Tais formas reproduzem o aspecto exterior das coisas por meio de elementos visuais que funcionam mimeticamente. Para cada uma delas, seguindo a lógica peirceana, há três submodalidades, correspondendo ao fato de ser uma possibilidade, um existente, e uma lei ou regra geral. Assim, as formas figurativas se subdividem em figura como qualidade, registro e convenção. Novamente, cada uma delas se subdivide, e as formas figurativas como registro, que importam para a análise de embalagens, se subdividem agora em registro imitativo, físico e por convenção. Aqui a reprodução tem uma conexão real com o objeto, é um registro físico. Isso faz que os efeitos que predominem sejam os vinculados à constatação por parte do consumidor.

Retomamos o que foi mencionado para a embalagem anteriormente analisada (Figura 1) - em relação aos nomes da marca e da linha de xampu que são registrados em letras maiúsculas e grandes, em preto e vermelho -, que a força da grafia intensifica os interpretantes vinculados à constatação, que levam o consumidor a identificar o produto, um xampu da marca Seda para cabelos de mulheres negras. Há de se enfatizar ainda que o termo Keraforce - uma espécie de junção de keratin com force (queratina com força, em português) - atesta a eficácia do produto. De um lado, por trazer a ciência (as propriedades da queratina); de outro, por impregnar o produto - com força - com a força da proteína. A parte superior do produto - o tom terroso -, por permitir associação à cor da pele (escura), também reforça os efeitos de constatação no intérprete.

Em relação às regras compartilhadas culturalmente e que um olhar generalizante tende a captar, destacamos os vinculados às cores, inicialmente. $\mathrm{O}$ contraste preto/vermelho, presente no nome da marca e na linha de produtos, bem como as palavras na parte de trás da embalagem, reaviva ambiguidades - noite/dia, escuro/claro, passivo/ativo, pois como esclarecem Chevalier e Gheerbrant (2008), enquanto o preto exprime a passividade, o vermelho incita à ação e lança seu brilho sobre todas as coisas como um sol. Com isso, a embalagem cria uma ambiência ambígua que faz o intérprete atentar para a força do produto, para o binômio Seda/força. Enfatizam a força e mesclam sensualidade nos tons terrosos que, como explicam Chevalier e Gheerbrant (2008), podem ser associados à terra fértil, ou à fertilidade feminina, e os avermelhados, que podem ser associados à força impulsiva, a Eros - pulsão de vida -, ao sensual. 
Novamente, para algum consumidor com conhecimento sobre design de embalagens ou sobre o percurso da Seda no mercado, é possível que os efeitos sejam deles decorrentes. A embalagem exibe um design mais arrojado que a anterior, ao se moldar ao toque - às mãos - com suas formas arredondadas.

No âmbito deste artigo, ressaltamos que a marca abrange diferentes tipos de cabelos, ou seja, ela considera a possibilidade da existência de cabelos cacheados e mostra que eles estão associados ao escuro. Embora a embalagem (Figura 2) construa uma ambiência de maior sensualidade e seja mais convidativa ao consumidor que a anterior (Figura 1), ambas, predominantemente, geram efeitos de constatação, de identificação do produto e do possível consumidor. Na segunda, a pele escura se destaca.

A visibilidade do escuro contribui para preencher a linha pontilhada mencionada por Mbembe (2017) - que envolve o processo de construção da identidade cultural do Negro. Em relação à primeira fase desse processo, a visibilidade - do escuro e dos cachos a ele associados - traz a relação claro/escuro para a superfície, exibe a aparência do Negro aqui e agora e pode contribuir para a formação de comunidades, tal como preconiza Mbembe (2017), quando esclarece que a volta da comunidade permite atar o passado ao presente. Aqui no caso, trata-se de retomar aspectos da aparência do Negro.

Na perspectiva de Sodré (1999), esse movimento vai ao encontro do paradigma que ele denominou de africanismo e, em relação às ideias de Mbembe (2017), consideramos que se trata da busca por respostas para identificar o Negro no contexto em que vive, aqui e agora. No entanto, isso não se faz sem o resgate das etapas da primeira fase do processo de construção da identidade cultural que identifica o Negro à África. As próximas embalagens a serem analisadas (Figura 3) são de cremes para pentear cabelos, da linha Boom, lançada em 2017. Vamos analisar, de modo geral, as embalagens, e depois colocar em destaque a embalagem do creme de pentear para cabelos crespos e crespíssimos.

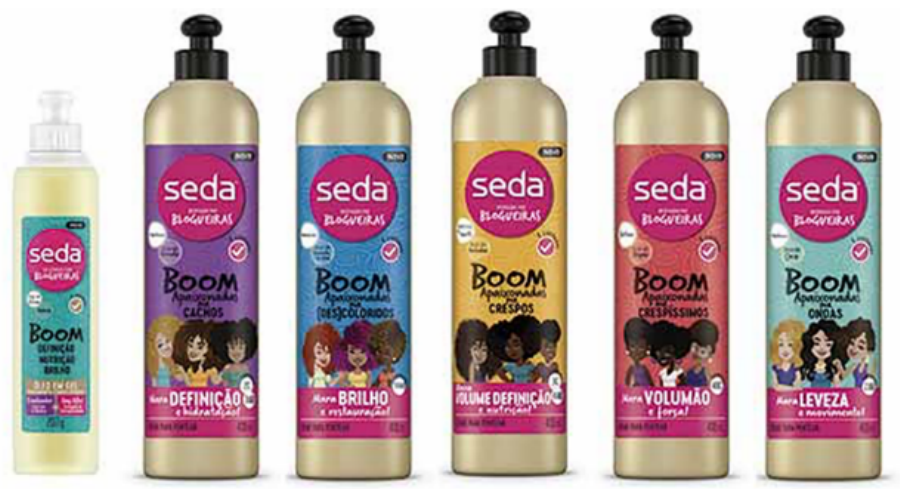

Figura 3. Crespos e crespíssimos: o reino do escuro.

Fonte: Seda (2020).

De modo geral, as embalagens que exibem uma profusão de cores e a forma cilíndrica, resultado de um design convencional para produtos de limpeza, grafias diversas e nas cores branca e preta, fazem que os interpretantes (ou efeitos gerados), predominantemente, permaneçam na seara da constatação, mas envolto em sensações de alegria, espontaneidade, liberdade. Vejamos a análise de duas embalagens (Figuras 4 e 5). 


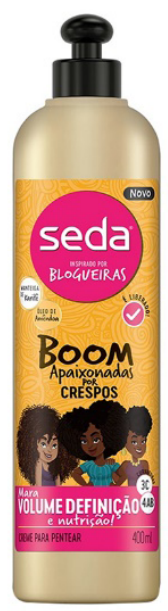

Figura 4. Xampu para cabelos crespos.

Fonte: Unilever (2020).

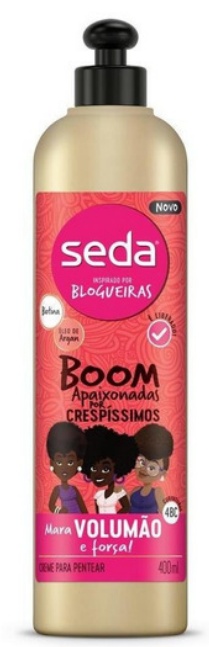

Figura 5. Xampu para cabelos crespíssimos.

Fonte: Unilever (2020).

Iniciamos com os aspectos qualitativos. As cores amarela e vermelha contribuem para construção de uma ambiência que gera efeitos vinculados à alegria, à sensualidade, efeitos em que os sentidos se afloram. A forma cilíndrica e as imagens - em formas figurativas - registros imitativos - podem contribuir para geração de interpretantes vinculados à espontaneidade, à alegria. Há uma ambiência convidativa para o consumidor, portanto. A forma figurativa, conforme Santaella (2001), é um registro imitativo mimético em relação àquilo que registra, ou seja, o seu traçado imita ou se assemelha à forma visível do objeto. Isto tira o impacto da conexão com o objeto real, o que contribui na geração de interpretantes, com vínculos feitos de modo mais ameno com o real, ou seja, não há choque bruto e, se houver, ele é amenizado.

Passando do olhar contemplativo, damos lugar ao olhar observacional, que capta pistas, marcas que remetem o consumidor a outros existentes. 
A forma cilíndrica da embalagem, usual para produtos de limpeza, remete o consumidor a tais produtos. A assepsia dá o tom, portanto. As imagens registro imitativo - por se valerem de traços que lembram os feitos à mão, desenhos, podem remeter o consumidor ao universo da infância. As grafias diversas e nas cores preta e branca também sugerem movimento, agregando maior descontração à ambiência mencionada. Desse modo, os aspectos referenciais permitem a identificação do produto, mas não os desvinculam de sensações de alegria, movimento e descontração.

O olhar generalizante retoma os simbolismos das cores, da forma e das imagens. Conforme esclarecem Chevalier e Gheerbrant (2008), "intenso, violento, agudo até a estridência, ou amplo e cegante como um fluxo de metal em fusão, o amarelo é a mais quente e expansiva, a mais ardente das cores” (p. 40), o que permite ao consumidor ou intérprete associar - pela presença do escuro, da mulher negra com cabelos crespos - tal expansividade a estereótipos do negro, como o que menciona Mbembe (2017) sobre o Negro ser "dotado de uma petulância excessiva, dominado pela alegria”. A cor avermelhada no fundo do 'rótulo' da embalagem, por sua vez, pode levar o consumidor a associar a embalagem a algo proibido, ou seja, compreender o vermelho como um sinal de transgressão em relação à proibição da libido, das pulsões sexuais, um estereótipo da mulher negra, enquanto figura sensual e exótica.

Amenizando o impacto do registro de algo por pura conexão com o real, as figuras são registros imitativos, desenhos de mulheres negras, que agregam maior calor à ambiência construída pela imagem, por resgatar o gesto, uma vez que lembram desenhos, de imagens feitas à mão. Tal forma de registro, como mencionamos na esteira de Santaella (2001), contribui para gerar interpretantes na seara do emocional, pois tem o efeito do choque amenizado, pela distância que impõe do real sem deixar de a ele se referir. Ele resgata o escuro, que aparece em diversos graus, com os cabelos crespos e crespíssimos. A figura não perde o poder de referência, no entanto, ele é amenizado.

Aqui, embora o design não seja inovador, a forma cilíndrica, usual para produtos de limpeza, faz que a embalagem seja vista como familiar, o que a aproxima do consumidor. Aliada à familiaridade vem o efeito de assepsia, que é bem-vindo na contramão do movimento de emancipação do escuro. Em geral, a embalagem permanece diante do consumidor com certa ambiguidade. Ela exibe o escuro - a pele escura e os cabelos crespos que são crespíssimos -, sem deixar de reavivar - suavemente estereótipos do negro. No entanto, em relação à embalagem anterior, esta agrega maior envolvimento com o escuro.

As embalagens analisadas mostram o movimento de exposição do escuro - no confronto com o claro - o que pode contribuir para o resgate da aparência - como um movimento e uma ação preparatória para a vinda de ações para ele falar de si próprio e no lugar em que vive, a segunda etapa do processo de construção da identidade cultural do Negro, conforme ressalta Mbembe (2017).

Embora não possamos conjeturar sobre o real interesse da marca, que pode ser o de alargar a quantidade de consumidores ao abarcar as mulheres de cabelos crespos e crespíssimos, a marca - por meio das embalagens - torna visível o escuro e põe os cabelos crespos e crespíssimos diante dos olhos de claros e escuros como uma possibilidade real. Reforça esse movimento - dos cabelos que explodem - o termo boom - que pode ser traduzido como um som ressonante e profundo, ou por fazer prosperar vigorosamente e rapidamente. 
Assim, metaforicamente pode ser traduzido por "deixa ser o crespo e o crespíssimo”, já que eles são vigorosos e estonteantes... aparecem ao olhar do outro - como num boom, uma explosão de cabelo.

Ainda pelas palavras, as consumidoras, no caso, se identificam como "apaixonadas pelo crespo" ou "apaixonadas pelo crespíssimo". A marca, ou o produto, reafirma a identificação das consumidoras com seus cabelos, com aspectos de sua aparência. O termo "apaixonada" concretiza, simbolicamente, a existência de um ego afetivo - por parte da consumidora - que conduz suas escolhas, o que pode incitar a busca apaixonada também pela identidade cultural... pela sua verdade em seu próprio território.

\section{CONSIDERAÇÕES FINAIS}

Cientes de que olhar para um detalhe de produtos para cabelos não dá conta de explicar o entrecruzamento das etapas do processo de construção de identidade cultural do negro, concluímos este artigo com o desejo de que ele tenha trazido à tona a questão das etapas desse processo e que as relações claro/escuro estão ainda latentes no nosso cotidiano. A marca, nesse aspecto, pode não sensibilizar a mulher negra para a importância de caminhar no processo de construção da identidade cultural, uma vez que introduz denominações - para os cabelos - com gradações do crespo e exibem os cabelos “indesejáveis” paulatinamente. A Seda não firma a etapa do processo de construção da identidade cultural do negro no sentido que ele - como enfatiza Mbembe - construa a sua identidade, a partir do seu território, dizendo quem ele é. Ela contribui - de modo muito tímido - para identificar a mulher negra no que ela tem de diferente.

As marcas devem atentar para todas as nuances do processo de construção da identidade cultural do negro, para assim mostrar como a comunicação via produção ou interpretação das manifestações da marca, de toda ordem, pode contribuir para lançar luz em tal processo e talvez, no futuro, corroborar para que os conflitos inerentes à convivência com o outro - aqui, o negro - sejam erradicados.

No caso das manifestações de uma marca - para os consumidores, em geral, independentemente de ser claro ou escuro - deve-se primar pelo conhecimento relativo aos processos de construção de identidade do negro, e não só buscar ampliação da quantidade de consumidores. Talvez o cuidado maior nessa produção propicie, de fato, um aumento no consumo.

\section{REFERÊNCIAS}

ARANTES, Dariane Lima. Celebrando nossos corpos, encrespando nossos fios: a transição capilar como política de visibilidade em narrativas autobiográficas de mulheres negras. 2019. Dissertação (Mestrado em Comunicação e Práticas de Consumo) - Escola Superior de Propaganda e Marketing, São Paulo, 2019

BELMIRO, Dalila Maria Musa. E não sou eu uma mulher?: o feminismo e a identidade negra na construção da celebridade Taís Araújo. 2019. Dissertação (Mestrado em Comunicação Social) Pontifícia Universidade Católica de Minas Gerais, Belo Horizonte, 2019.

CARVALHO, Mayra Bernardes Medeiros de. Esse Boom é nosso?: discursos sobre a transição capilar na publicidade de cosméticos. 2019. Dissertação (Mestrado em Comunicação Social) Universidade Federal de Minas Gerais, Belo Horizonte, 2019. 
CHEVALIER, Jean; GHEERBRANT, Alain. Dicionário de símbolos: mitos, sonhos, costumes, gestos, formas, figuras, cores, números. Rio de Janeiro: José Olympio, 2008.

DRIGO, Maria Ogécia; SOUZA, Luciana. C. P. Aulas de semiótica peirceana. São Paulo: Annablume, 2013.

LIPOVETSKY, Gilles; SERROY, Jean. A cultura-mundo: resposta a uma sociedade desorientada. São Paulo: Companhia das Letras, 2011.

MARTINS, Carlos Augusto de Miranda. Racismo anunciado: o negro na publicidade no Brasil (1985-2005). 2009. Dissertação (Mestrado em Ciências da Comunicação) - Universidade de São Paulo, São Paulo, 2009.

MBEMBE, Achille. Crítica da razão negra. Lisboa: Antígona, 2017.

SANTAELLA, Lucia. Matrizes da linguagem e pensamento: sonora, visual, verbal: aplicações na hipermídia. São Paulo: Iluminuras, 2001.

SANTAELLA, Lucia. Semiótica Aplicada. São Paulo: Pioneira Thomson Learning, 2018.

SEMPRINI, Andrea. A marca pós-moderna: poder e fragilidade da marca na sociedade contemporânea. São Paulo: Estação das Letras, 2006.

SODRÉ, Muniz. Claros e escuros: identidade, povo e mídia no Brasil. Petrópolis: Vozes, 1999. 